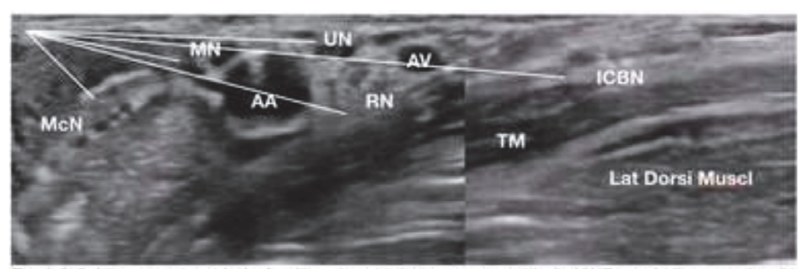

Abstract 150 Figure 1 and 2 Ultrasound guided of axillary brachial plexus nerver block (AXB) and Ultrasound guided Intercostobrachial nerve block (ICBN). MN (Median nerve), UN (Ulnar nerve), McN (Musculocutaneous nerve), RN (radial nerve), TM (Teres Major muscle), AA (axillary artery), AV (axillary vein)

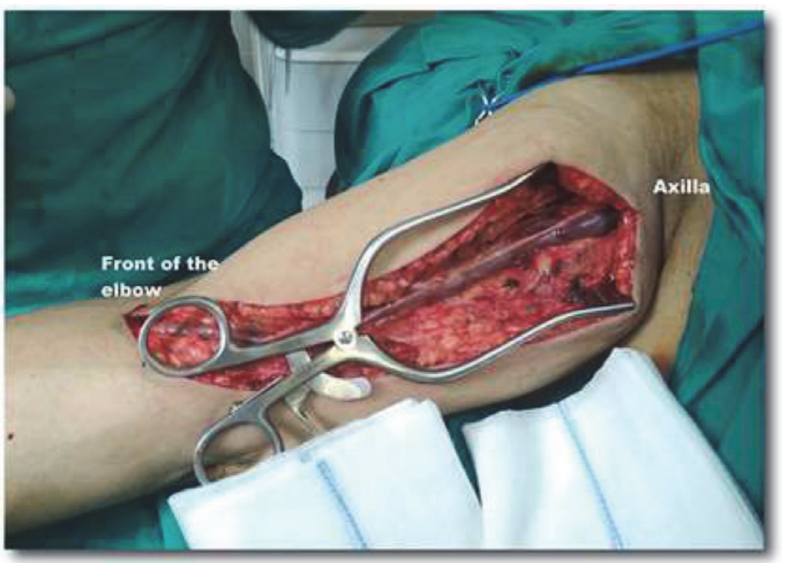

Abstract 150 Figure 3 A continuous longitudinal incision over the basilic vein from the axilla to the medial epicondyle of the humerus for brachial artery to basilic vein anastomosis and anterior and superficial relocation of basilica vein

respectively with a BBraun Stimuplex 21G $100 \mathrm{~mm}$ insulated needle.

The surgery involved a continuous longitudinal incision over the basilic vein from the axilla to the medial epicondyle of the humerus for brachial artery to basilic vein anastomosis and anterior and superficial relocation of basilica vein (figure 3). Surgical duration was two hours.

Results The patients remained pain free intraoperatively with no supplemental LA required and completed uneventfully. Patients were discharged on the same day and the numbness resolved within 24 hours.
Conclusions We demonstrated how TBBAVF surgery is successfully managed by an ICB nerve block and axillary BPB under ultrasound guidance. Future studies are required to explore this technique, including dosage-finding study.

\section{SONOCLUB: INCREASING ACCESS TO REGIONAL ANAESTHESIA PLAN A BLOCKS}

MSF Chong*, S Patel, D McNaughton, R Pilling. Chelsea and Westminster Hospital, London, UK

\subsection{6/rapm-2021-ESRA. 151}

Background and Aims The new RCoA 2021 Curriculum requires anaesthetic trainees to 'deliver a range of safe and effective regional anaesthetic techniques to cover the upper and lower limb, chest and abdominal wall independently' [1]. RA-UK have highlighted inconsistences in training and recommend core competency in high value Plan A blocks [2]. We implemented a weekly Sonoclub teaching program to cover all 7 Plan A blocks to raise the standards in ultrasound guided regional anaesthesia (UGRA) in our hospital (figure 1).

Methods Sonoclub sessions, which were organised by regional fellows from April to June 2021, lasted one hour encompassing lectures to help pass FRCA/EDRA and 'block of the week' scanning. Equipment included a computer, two ultrasound machines, two beds and willing participants. We conducted a pre- and post- course survey to evaluate trainees' training and competency in regional anaesthesia.

Results 17 anaesthetic trainees (CT1-ST7) replied to the preand post- course questionnaire with an average attendance of 3 Sonoclub sessions. $24 \%$ agreed and $77 \%$ strongly agreed that Sonoclub improved their knowledge and skills in regional anaesthesia. Using a 5-point Likert scale, we found considerable improvements in the practice of obtaining consent, sonoanatomy of Plan A blocks (figure 2), managing complications

\begin{tabular}{|l|l|}
\hline KNOWLEDGE & SKILLS \\
\hline Ultrasound & Plan A - UL: Axillary \\
\hline Complications & Plan A - Trunk: Erector Spinae Plane \\
\hline Pharmacology & Plan A - LL: Adductor Canal \\
\hline Consent & Plan A - UL: Interscalene \\
\hline Anticoagulants & Plan A - LL: Femoral Nerve, FIB \\
\hline Nerve stimulators & Plan A - Trunk: Rectus Sheath \\
\hline Local anaesthetic toxicity & Plan A - LL: Popliteal Sciatic \\
\hline
\end{tabular}

Abstract 151 Figure 1 Weekly Sonoclub timetable 
"I can provide safe and effective regional anaesthesia"
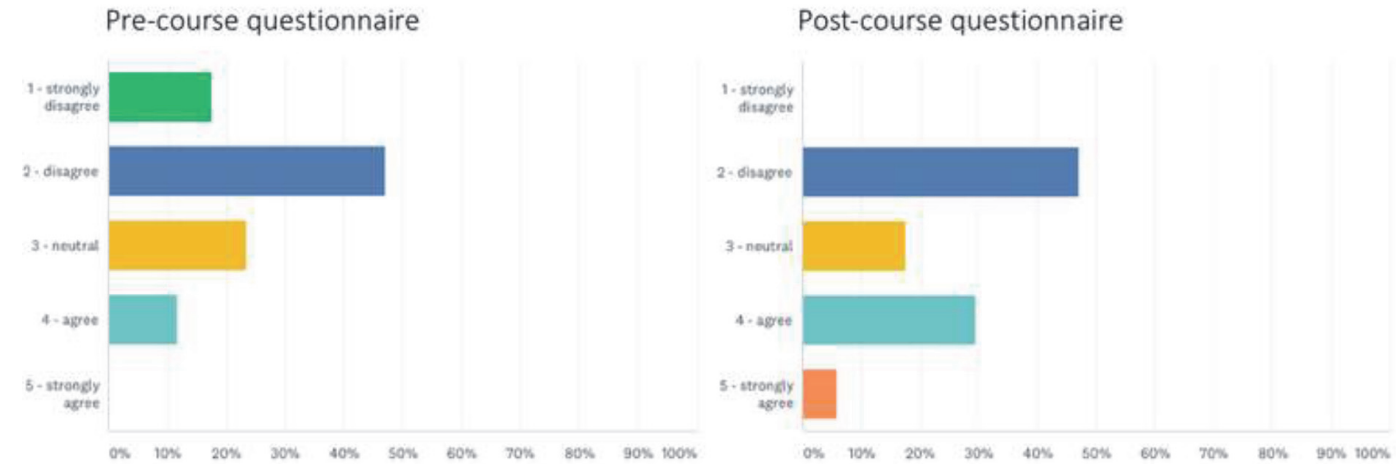

Abstract 151 Figure 3 Pre- and post-course questionnaire for providing safe and effective regional anaesthesia

and providing safe and effective regional anaesthesia (figure 3).

Conclusions We have shown regular departmental Sonoclub teaching improves training and competency in regional anaesthesia. We recommend Plan A blocks are taught on a regular basis in all hospitals. It is cheap, easy to implement and improves standards in regional anaesthesia.

\section{REGIONAL ANESTHESIA FOR CORRECTION OF CLAVICLE FRACTURE IN A POLYTRAUMA PATIENT DIAGNOSED WITH SEVERE OBSTRUCTIVE SLEEP APNEA (OSA)}

D Gonçalves, C Sousa* , F Teixeira, D Roriz, M Sá Vieira, C Sampaio. Centro Hospitalar Trásos-Montes e Alto Douro, Vila Real, Portugal

\subsection{6/rapm-2021-ESRA.152}

Background and Aims Clavicle surgery can be performed under general or regional anesthesia; the latter is preferred when there's interest in avoiding complications associated with general anesthesia.

Multiple rib fractures are associated with significant morbidity such as ventilatory compromise, increased rate of atelectasis, lung contusion and pneumonia. If invasive mechanical ventilation can be avoided, intensive care unit stay and complications from mechanical lung ventilation can be prevented.

Methods A 78-year-old male patient weighing $80 \mathrm{Kg}$ and with severe OSA presented to our emergency department with a left clavicle fracture and left costal arc fractures from T1 to T10 after an accidental fall. After stabilization the patient was scheduled for surgical correction of the clavicle fracture.

After obtaining consent to perform surgery under regional anesthesia and conscious sedation, we administered $50 \mathrm{mcg}$ of fentanyl and initiated a dexmedetomidine infusion.

We performed different ultrasound guided nerve blocks with Ropivacaine $0.5 \%$ : $5 \mathrm{~mL}$ were administered at the interscalene groove to block the brachial plexus, $5 \mathrm{~mL}$ targeted at the supraclavicular nerves and $10 \mathrm{~mL}$ at the clavipectoral fascial plane.

Results The patient reported no pain throughout the procedure and there was no ventilatory compromise or need for intubation. In the first 24 postoperative hours, the patient did not report pain, either at rest or movement, without need of rescue analgesia.

Conclusions The use of peripheral nerve blocks allowed for surgical correction of clavicle fracture in our patient, while avoiding pulmonary complications associated to invasive mechanical ventilation, difficult ventilatory weaning, and prolonged stay at the intensive care unit.

\section{ULTRASOUND-GUIDED SERRATUS ANTERIOR PLANE BLOCK (US-SAP BLOCK) AND ULTRASOUND-GUIDED PARASTERNAL BLOCK (US-PSB) FOR S-ICD IMPLANTATION IN SEVERE DILATED POST-ISCHAEMIC CARDIOMYOPATHY: A CASE STUDY}

F Marrone*, S Paventi, M Tomei, M Bosco. ASL ROMA 1 - Ospedale Santo Spirito, Roma, Italy

\subsection{6/rapm-2021-ESRA.153}

Background and Aims s-ICD (subcutaneous-Implantable Cardioverter Defibrillator) is crucial in patients at risk of cardiac adverse events. Positioning technique requires in deep sedation or general anesthesia two incisions with generator placed between 'serratus' and 'latissimus' muscles while defibrillator lead goes through parasternal incision. We report a case of s-ICD implantation under regional anesthesia and sedation.

Methods A male patient, aged-44, BMI 21, severe postischaemic cardiomyopathy (EF 26\%, TAPSE $14 \mathrm{~mm}$, PAP 67 $\mathrm{mmHg}$, BNP 1428), ASA 3, was scheduled for s-ICD implantation. After valid informed consent, US-SAPB was performed aseptically, using $80-\mathrm{mm}$ echogenic, atraumatic needle, at mid-axillary line, fifth rib, left hemithorax. Anatomy and needle's tip correctly viewed. After negative aspiration, in boluses, $0.5 \%$ ropivacaine $20 \mathrm{ml}$ were injected. In full asepsis US-PsB, left second and fourth intercostal spaces, was performed; 50-mm echogenic, atraumatic needle. Anatomy and needle's tip correctly viewed. $0.375 \%$ ropivacaine $4 \mathrm{ml}$ was injected for each block. No complications. Pneumothorax was excluded by LUS. $10-\mathrm{MHz}$ linear probe was used. MAC (Monitored Anesthesia Care) was provided. Patient was sedated with midazolam $2 \mathrm{mg}$ e.v., propofol 50 $\mathrm{mg}$ e.v. and dexmedetomidine in continuous intravenous infusion $(0,5 \mathrm{mcg} / \mathrm{kg} / \mathrm{h})$, in spontaneous breathing and $30 \%$ O2 mask.

Results Operation began 15 minutes after beginning of MAC, 45 minutes after blockades placement. Patient vital signs, although severely sick, remained stable. No pain reported. Patient was observed in PACU and discharged with Aldretescore 10 . 